\title{
Effect of clary sage (Salvia sclarea L.) essential oil on paper packaging materials
}

\section{Iliana Kostova1, Veska Lasheva², Hafize Fidan², Darina Georgieva ${ }^{1}$, Stanka Damyanova ${ }^{1}$, Albena Stoyanova ${ }^{3}$}

\author{
1 - Angel Kanchev" University of Ruse, Razgrad Branch, Razgrad, Bulgaria \\ 2 - University of Chemical Technology and Metallurgy, Sofia, Bulgaria \\ 3 - University of Food Technologies, Plovdiv, Bulgaria
}

Keywords:

Packaging

Paper

Clary sage

Salvia sclarea

Essential oil

Antimicrobial

Article history:

Received 14.07.2019

Received in revised form

26.10.2019

Accepted 30.06.2020

Corresponding author:

Hafize Fidan

E-mail:

hfidan@abv.bg

DOI: $10.24263 / 2304$

974X-2020-9-2-3

\section{Abstract}

Introduction. The aim of research - to determine the effect of clary sage (Salvia sclarea L.) essential oil on paper packaging materials.

Materials and methods. Three packaging materials have been studied based on paper coated with clary sage essential oil. The chemical composition of the clary sage essential oil is determined chromatographically. Antimicrobial effect of essential oil was determined against Gram-positive, Gram-negative bacteria, yeasts, and fungi using the agar diffusion method.

Results and discussion. The chemical composition of the clary sage essential oil showed a predominant amount of oxygenated monoterpenes $(83.43 \%)$, followed by monoterpene hydrocarbons (7.86\%), and sesquiterpene hydrocarbons $(5.16 \%)$. The major components of the clary sage essential oil were linalyl acetate, $\beta$-linalool, $\alpha$ terpineol, limonene, and geranyl acetate that determined the antimicrobial action of the oil.

The essential oil exhibited a fungicidal action against the tested molds and yeasts. Its high antimicrobial properties could be probably due to the high content of linalyl acetate $(40.31 \%)$ and $\beta$-linalool $(22.72 \%)$.

Our results showed high fungicidal efficacy for the three types of packaging materials. The suppressive action against $C$. albicans during the investigated shelf life period was about $100 \%$. It was found a high efficiency of the recycled paper against $A$. brasiliensis $(99.2 \%-81.9 \%)$. It was determined that the bactericidal effect of the tested packaging materials was lower than the Gram-negative bacterium $S$. abony.

Conclusions. Clary sage essential oil could be used as an antimicrobial agent in the food industry due to its antimicrobial properties, in order to improve the quality of the products and extend their shelf life. 


\section{Introduction}

Clary sage essential oil is obtained by steam distillation of flowering inflorescences of the plant. The main constituents in the essential oil are linalyl acetate $(45-65 \%)$ and $\beta$ linalool (15-25\%). It has a musky, bittersweet smell [1]. It has an antibacterial and antiseptic action $[2,3]$. It is mainly used in the perfumery, cosmetics, aromatherapy, and phytotherapy. The leaves and inflorescences are used also for flavoring of some foods - meat, dairy, vegetables, etc. [1].

The usage of plant extracts and essential oils is preferred in the development of novel active packings due to the ability of the antimicrobial substance to contact the product or to penetrate food [4,5].The interest in the usage of essential oils in packing systems has increased in recent years due to their high antimicrobial activity. An antimicrobial active packaging developed based on packing paper and essential oils has been used successfully in the storage of strawberries [6].

The aim of the present study is to develop a wrapping paper with the clary sage essential oil and to study its antimicrobial efficacy.

\section{Materials and methods}

\section{Materials}

Packaging papers. Three types of wrapping papers were used - 100\% recycled paper weighing $70 \mathrm{~g} / \mathrm{m}^{2}, 100 \%$ bleached pulp $40 \mathrm{~g} / \mathrm{m}^{2}$ and $100 \%$ unbleached pulp $40 \mathrm{~g} / \mathrm{m}^{2}$.

Essential oil. The clary sage essential oil was provided by a manufacturer in Bulgaria.

\section{Methods}

Paper analysis. Microscopic analysis was performed to demonstrate the composition of the fibrous material from which the packaging papers were obtained.

From the physico-mechanical properties, the length of tear of the test paper samples was determined. The samples used have been analyzed before and after treatment with clary sage essential oil [7].

Oil analysis. The physical and chemical parameters (appearance, color, odor, relative density, refraction, and acid number) of the clary sage essential oil were determined [8].

The GC-MS analysis was carried out with an Agilent 5975C MSD system coupled to an Agilent 7890A gas chromatograph (Agilent Technologies Inc., Santa Clara, CA). Agilent J\&W HP-5MS column $(0.25 \mu \mathrm{m}, 30 \mathrm{~m} \times 0.25 \mathrm{~mm})$ was used with helium as a carrier gas $\left(1.0 \mathrm{~mL} \mathrm{~min}^{-1}\right)$. The operational conditions were: oven temperature $35^{\circ} \mathrm{C} / 3 \mathrm{~min}, 5^{\circ} \mathrm{C} / \mathrm{min}$ to $250{ }^{\circ} \mathrm{C}$ for $3 \mathrm{~min}$, total run time $49 \mathrm{~min}$; injector temperature $260{ }^{\circ} \mathrm{C}$; ionization voltage 70 $\mathrm{eV}$; ion source temperature $230{ }^{\circ} \mathrm{C}$; transfer line temperature $280{ }^{\circ} \mathrm{C}$; solvent delay $4.25 \mathrm{~min}$ and mass range 50 - $550 \mathrm{Da}$. The MS was operated in scan mode. One $\mu \mathrm{L}$ of the sample was injected into the GC/MS system at a split ratio of 30:1. The GC analysis was carried out using an Agilent 7890A GC system; FID temperature $270{ }^{\circ} \mathrm{C}$. In order to obtain the same elution order with GC/MS, simultaneous triplicate injections were done by using the same column and the same operational conditions. 


\section{Food Technology}

The identification of compounds was made by comparing their mass spectra with those from mass spectra libraries and by comparing the literature and estimated Kovat's (retention) indices that were determined using mixtures of homologous series of normal alkanes from $\mathrm{C}_{8}$ to $\mathrm{C}_{40}$ in hexane, under the conditions described above [9]. The percentage ratio of volatile components was computed using the normalization method of the GC/FID peak areas.

Determination of antimicrobial activity. The antimicrobial activity of clary sage essential oil was tested against test microorganisms provided by the National Bank for Industrial Microorganisms and Cell Cultures in Sofia, Bulgaria: Gram-positive bacteria: Staphylococcus aureus ATCC 6538, Bacillus subtilis ATCC 6633; Gram-negative bacteria: Escherichia coli ATCC 8739, Pseudomonas aeruginosa ATCC 9027, Salmonella abony NTCC 6017; yeast: Saccharomyces cerevisiae ATCC 2601, Candida albicans ATCC 10231; and fungal strain: Aspergillus brasiliensis ATCC 16404.

The antimicrobial activity was determined by the agar well diffusion method with a well size of $8 \mathrm{~mm}$. The growth media were Tryptic soy agar (Merck) for the tested bacterial strains and Sabouraud-Dextrose-Agar (Merck) for the yeast and fungi. The media were inoculated with a 24-h suspension of the bacterial species with a density of approximately $10^{7} \mathrm{CFU} \mathrm{mL}$ (turbidity: $0.5 \mathrm{McF}$ arland standards). Media melted and cooled to $50{ }^{\circ} \mathrm{C}$ were inoculated with the tested microorganisms and then equally dispensed into Petry dishes. Next, a hole with a diameter of $8 \mathrm{~mm}$ was punched aseptically with a sterile cork borer, and a volume $(50 \mu \mathrm{L})$ of the antimicrobial agent was placed into the well. After that, the agar plates were incubated at $37^{\circ} \mathrm{C}$ or $28^{\circ} \mathrm{C}$ for 24 or $72 \mathrm{~h}$ according to the microbial species. After cultivation, the distinct zone of growth inhibition around the wells was measured using a digital caliper. The diameter of the zones, including the diameter of the well, was recorded in $\mathrm{mm}$, for instance, up to 15 $\mathrm{mm}$ the microbial culture was poorly sensitive, from 15 to $25 \mathrm{~mm}$ it was considered sensitive, and over $25 \mathrm{~mm}$ it was considered as very sensitive. The tests were performed in parallel with solvent controls [10].

Determination of the antimicrobial properties of paper coated with clary sage essential oil. The clary sage essential oil was applied with a pump dispenser on both sides of each paper square $(5 / 5 \mathrm{~cm}$ squares $)$ and dried. The antimicrobial activity of coated papers was examined after $2 \mathrm{~h}, 24 \mathrm{~h}$, and 5 days. A $24 \mathrm{~h}$-culture was prepared from each bacterial test microorganism. With a wire loop, vegetative material was taken and suspended in $10 \mathrm{~mL}$ of saline. The suspensions prepared were with a cell concentration of about $10^{3} \mathrm{CFU} / \mathrm{mL}$. Yeast and mold suspensions were prepared in the same manner, but the cultures used were at the age of $48 \mathrm{~h}$ for yeast and $120 \mathrm{~h}$ for mold. In aseptic conditions with sterile tweezers, each square coated with essential oil was placed in a sterile petri dish. With sterile pipette on each square was dropped $0.1 \mathrm{~mL}$ of the prepared cell suspensions and carefully spread over the surface of the paper and then they were placed in a thermostat at $30-35^{\circ} \mathrm{C}$ for $2 \mathrm{~h}$. Aseptically with a sterile pipette, in every petri dish were dropped $20 \mathrm{~mL}$ of Tryptic soy agar for bacteria or Sabouraud-dextrose agar for yeast and molds. The following control samples were also prepared: clary sage essential oil and microorganism free paper and essential oil free paper with suspension from the current microorganism were obtained. Samples were cultivated in a thermostat at $30-35^{\circ} \mathrm{C}$ for $24-48 \mathrm{~h}$ for bacterial species and at $20-25^{\circ} \mathrm{C}$ for $48-72 \mathrm{~h}$ for yeast and $120 \mathrm{~h}$ for mold. The colonies grown in the petri dishes were encountered [10]. 


\section{Results and discussion}

The clary sage essential oil is a light yellow liquid with musky and bitter-sweet odor.

Indicators as appearance, color, odor, relative density refractive index, and an acid number of lary sage essential oil were presented in Table 1. The results are in agreement with the data found in the literature [1].

Indicators of clary sage essential oil

Table 1

\begin{tabular}{|l|c|}
\hline Indicators & Clary sage essential oil \\
\hline Appearance & Liquid \\
\hline Color & Light yellow \\
\hline Odor & Musky, bitter-sweet \\
\hline Relative density $\left(d_{20}^{20}\right)$ & $0.9034 \pm 0.00$ \\
\hline Refractive index $\left(n_{D}^{20}\right)$ & $1.4602 \pm 0.05$ \\
\hline Acid number $(\mathrm{mg} \mathrm{KOH} / \mathrm{g}$ clary sage essential oil) & $1.52 \pm 0.02$ \\
\hline
\end{tabular}

\section{Chemical composition of clary sage essential oil}

The chemical composition of the clary sage essential oil was shown in Table 2 .

In the clary sage essential oil were identified 30 constituents representing $98.97 \%$ of the total content of the oil as 5 of them were in concentrations above $1 \%$ and the rest 25 constituents were in concentrations under $1 \%$. The main constituents in the clary sage essential oil (above 3\%) were: linalyl acetate (40.31\%), $\beta$-linalool (22.72\%), $\alpha$-terpineol $(7.74 \%)$, limonene $(5.40 \%)$, and geranyl acetate $(4.63 \%)$. These constituents determined the antimicrobial properties of the clary sage essential oil $[2,3]$.

The differences between the essential oil yield in this study and that from other studies, reported in the literature $[1,11,12]$ are probably due to the climatic conditions in the respective locality where the plants were grown, and also to the plant parts processed and extracted.

The distribution of major groups of aroma substances in the clary sage essential oil was also shown in Table 2. Oxygenated monoterpenes and monoterpene hydrocarbons dominated in the clary sage essential oil.

The physico-mechanical parameters (length of the tear in the longitudinal direction and relative longitudinal extension) of three different types of papers were presented (Table 3).

The results showed that the paper coatings with clary sage essential oil affected their properties as the length of the tear in the longitudinal direction and relative longitudinal extension. A decrease in the physico-mechanical parameters (breaking length by about 200 $\mathrm{m})$ was indicated. The results showed that the loosening of the hydrogen bonds occurred when the clary sage essential oil has penetrated. These changes were not significant and the papers could be used for their intended purpose. 
Chemical composition of the clary sage essential oil

Table 2

\begin{tabular}{|c|c|c|c|}
\hline Name & $\mathbf{R T}^{\mathbf{1}}$ & $\mathbf{R I}^{2}$ & $\begin{array}{c}\text { Content, } \\
\% \text { of } \text { TIC }^{3}\end{array}$ \\
\hline$\alpha$-Pinene & 9.69 & 932 & 0.22 \\
\hline$\beta$-Pinene & 11.08 & 975 & 0.31 \\
\hline$\beta$-Myrcene & 11.51 & 988 & 1.49 \\
\hline p-Cymene & 12.64 & 1020 & 0.21 \\
\hline Limonene & 12.81 & 1025 & 5.40 \\
\hline cis-Linalyl oxide & 14.11 & 1067 & 0.37 \\
\hline Terpinolene & 14.56 & 1084 & 0.36 \\
\hline$\beta$-Linalool & 15.08 & 1090 & 22.72 \\
\hline$\alpha$-Terpineol & 17.94 & 1188 & 7.74 \\
\hline Linalyl formate & 18.40 & 1215 & 0.38 \\
\hline$\beta$-Citronellol & 18.81 & 1224 & 0.94 \\
\hline Nerol & 19.53 & 1230 & 0.41 \\
\hline Linalyl acetate & 19.75 & 1254 & 40.31 \\
\hline$\alpha$-Citral & 20.04 & 1268 & 0.43 \\
\hline Neryl formate & 20.25 & 1280 & 0.11 \\
\hline Geranyl formate & 20.82 & 1297 & 0.24 \\
\hline Linalyl propanoate & 21.76 & 1334 & 0.65 \\
\hline$\alpha$-Cubebene & 22.05 & 1345 & 0.88 \\
\hline Citronellyl acetate & 22.14 & 1350 & 0.85 \\
\hline Neryl acetate & 22.46 & 1361 & 2.78 \\
\hline Geranyl acetate & 23.01 & 1380 & 4.63 \\
\hline$\beta$-Cubebene & 23.19 & 1386 & 0.37 \\
\hline$\beta$-Bourbonene & 23.27 & 1389 & 0.23 \\
\hline$\beta$-Caryophyllene & 24.12 & 1420 & 1.54 \\
\hline$\beta$-Selinene & 25.63 & 1487 & 0.28 \\
\hline$\alpha$-Selinene & 25.80 & 1496 & 1.81 \\
\hline Spathulenol & 28.09 & 1577 & 1.92 \\
\hline Caryophyllene oxide & 28.58 & 1582 & 0.12 \\
\hline (2-Z,6-E)-Farnesyl acetate & 34.66 & 1821 & 0.20 \\
\hline n-Docosane & 40.53 & 2200 & 1.07 \\
\hline \multicolumn{3}{|c|}{ Total, \% } & 98.97 \\
\hline \multicolumn{3}{|c|}{ Aliphatic hydrocarbons, $\%$} & 1.08 \\
\hline \multicolumn{3}{|c|}{ Monoterpene hydrocarbons, $\%$} & 7.86 \\
\hline \multicolumn{3}{|c|}{ Oxygenated monoterpenes, \% } & 83.43 \\
\hline \multicolumn{3}{|c|}{ Sesquiterpene hydrocarbons, \% } & 5.16 \\
\hline \multicolumn{3}{|c|}{ Oxygenated sesquiterpenes, $\%$} & 2.26 \\
\hline \multicolumn{3}{|c|}{ Phenyl propanoids, $\%$} & 0.21 \\
\hline
\end{tabular}

1 - retention time, min;

2 - retention (Kovat's) index;

3 - identified at $>0.05 \%$ of TIC 
Table 3

Length of packing paper cuts

\begin{tabular}{|c|c|c|c|c|c|c|c|c|c|c|c|c|}
\hline \multirow{3}{*}{$\begin{array}{c}\text { Paper } \\
\text { kind }\end{array}$} & \multicolumn{4}{|c|}{ Bleached cellulose } & \multicolumn{4}{|c|}{ Unbleached cellulose } & \multicolumn{4}{|c|}{ Recycled paper } \\
\hline & 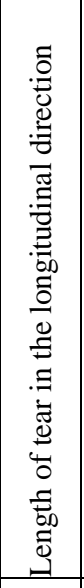 & 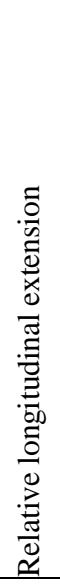 & 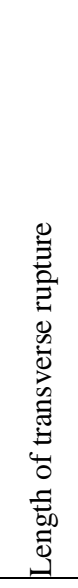 & 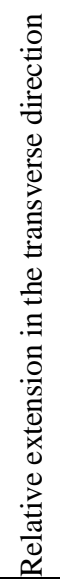 & 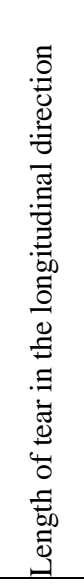 & 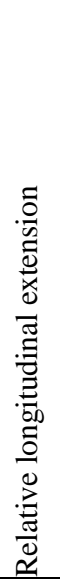 & 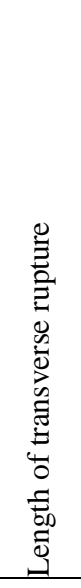 & 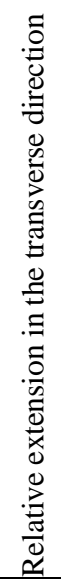 & 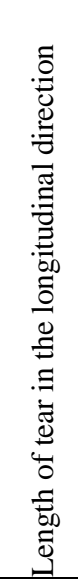 & 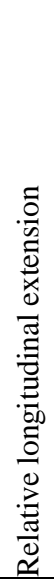 & 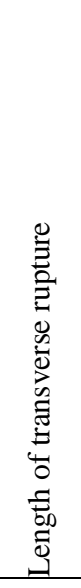 & 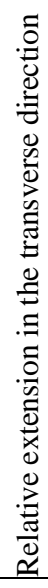 \\
\hline & $\mathrm{m}$ & $\%$ & $\mathrm{~m}$ & $\%$ & $\mathrm{~m}$ & $\%$ & $\mathrm{~m}$ & $\%$ & $\mathrm{~m}$ & $\%$ & $\mathrm{~m}$ & $\%$ \\
\hline $\begin{array}{l}\text { Untreated } \\
\text { with clary } \\
\text { sage essential } \\
\text { oil }\end{array}$ & 2500 & 1.4 & 2200 & 1.6 & 5800 & 1.0 & 1800 & 1.5 & 2800 & 0.8 & 1900 & 2.0 \\
\hline $\begin{array}{l}\text { Treated with } \\
\text { clary sage } \\
\text { essential oil }\end{array}$ & 2200 & 1.2 & 2000 & 1.4 & 5600 & 0.8 & 1600 & 1.2 & 2600 & 0.6 & 1600 & 1.8 \\
\hline
\end{tabular}

\section{Antimicrobial activity of clary sage essential oil}

The clary sage essential oil exhibited a fungicidal action against the tested strains of mold and yeast, with an inhibition zone diameter between 16.5 and $23.1 \mathrm{~mm}$ (Fig. 1). It was determined a bactericidal effect of clary sage essential oil on Gram-positive bacteria $S$. aureus $(18.6 \mathrm{~mm})$ and $B$. subtilis $(17.9 \mathrm{~mm})$ as the antimicrobial activity was determined to be lower against Gram-negative bacteria $S$. abony $(16.7 \mathrm{~mm}))$, E. coli $(15.8 \mathrm{~mm})$ and $P$. aeruginosa $(14.6 \mathrm{~mm})$. The antimicrobial properties of clary sage essential oil have been studied by other researchers [2,3]. We consider that there is a correlation between the antimicrobial activity of clary sage essential oil and its chemical composition [3, 13]. Its high antimicrobial properties against the investigated test-microorganisms could be probably due to the high content of linalyl acetate $(40.31 \%)$ and $\beta$-linalool $(22.72 \%)$. 


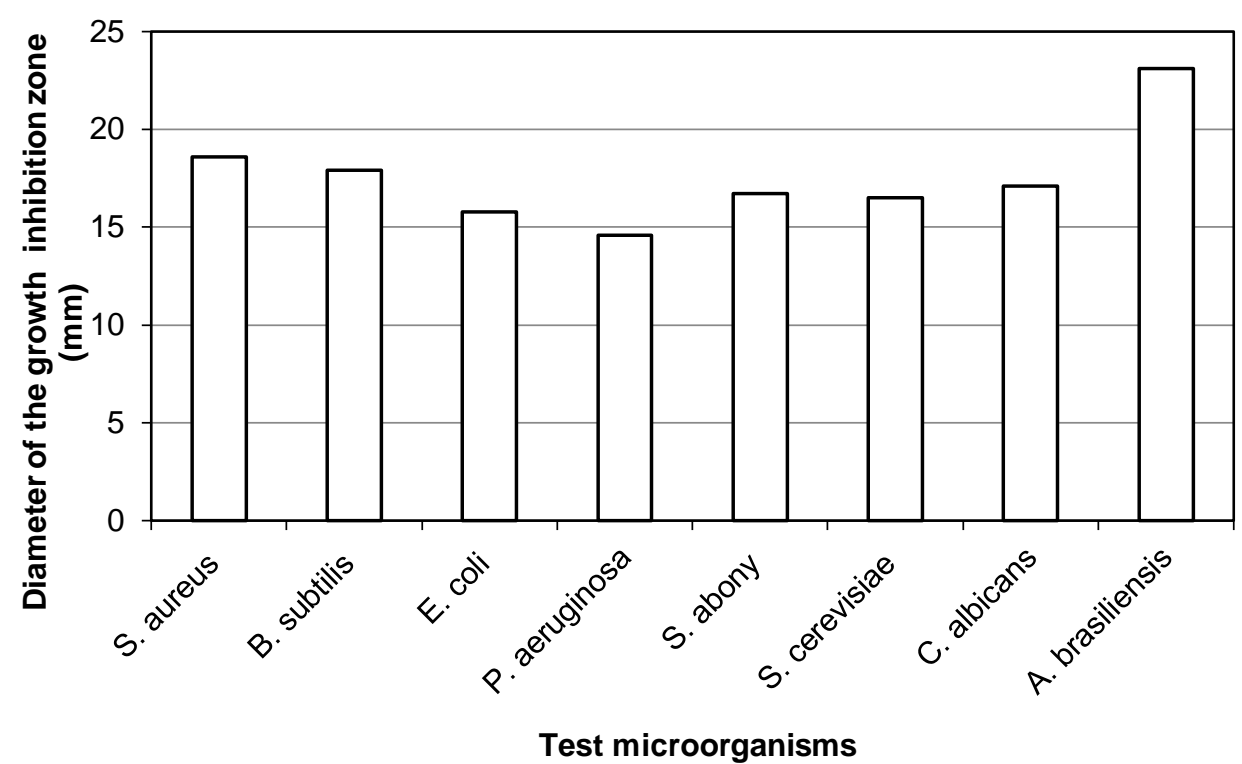

Figure 1. Antimicrobial activity of clary sage essential oil

Antimicrobial properties of paper coated with clary sage essential oil

The antimicrobial activity of different papers coated with clary sage essential oil was presented (Figure 2, 3 and 4).

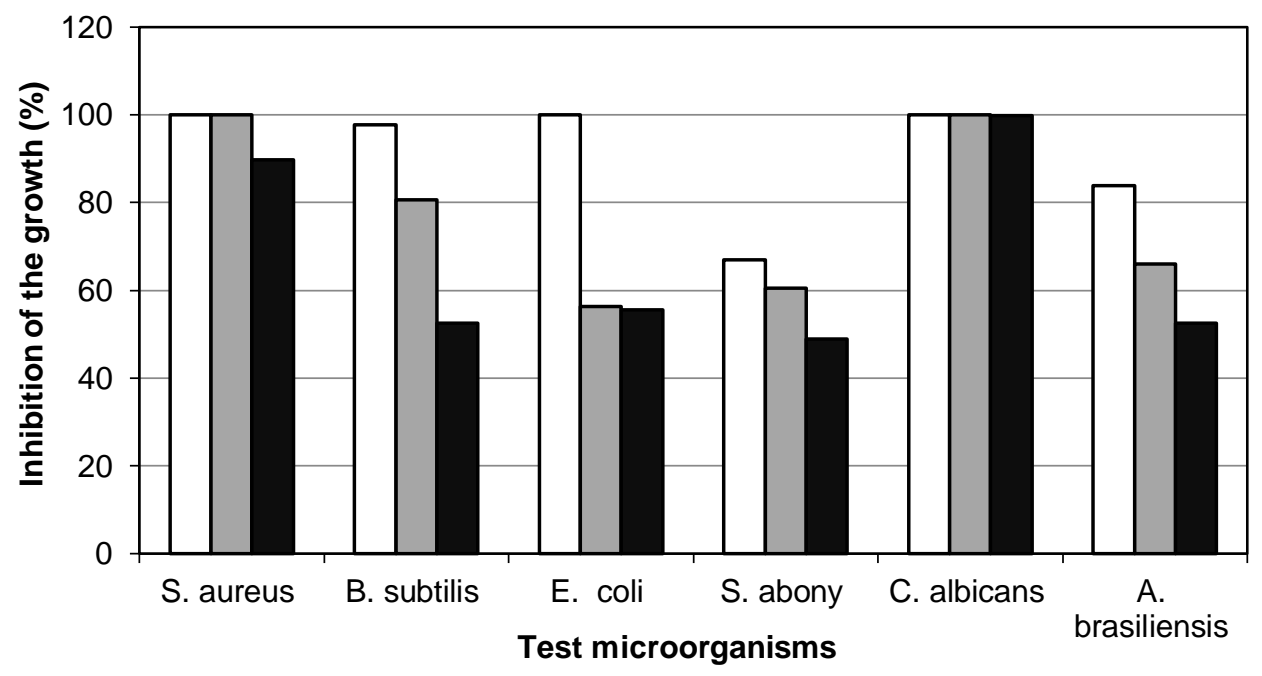

$\square 2$ hours $\square 24$ hours $\mathbf{5}$ days

Figure 2. The antimicrobial effectiveness of bleached cellulose wrapping paper coated with clary sage essential oil 


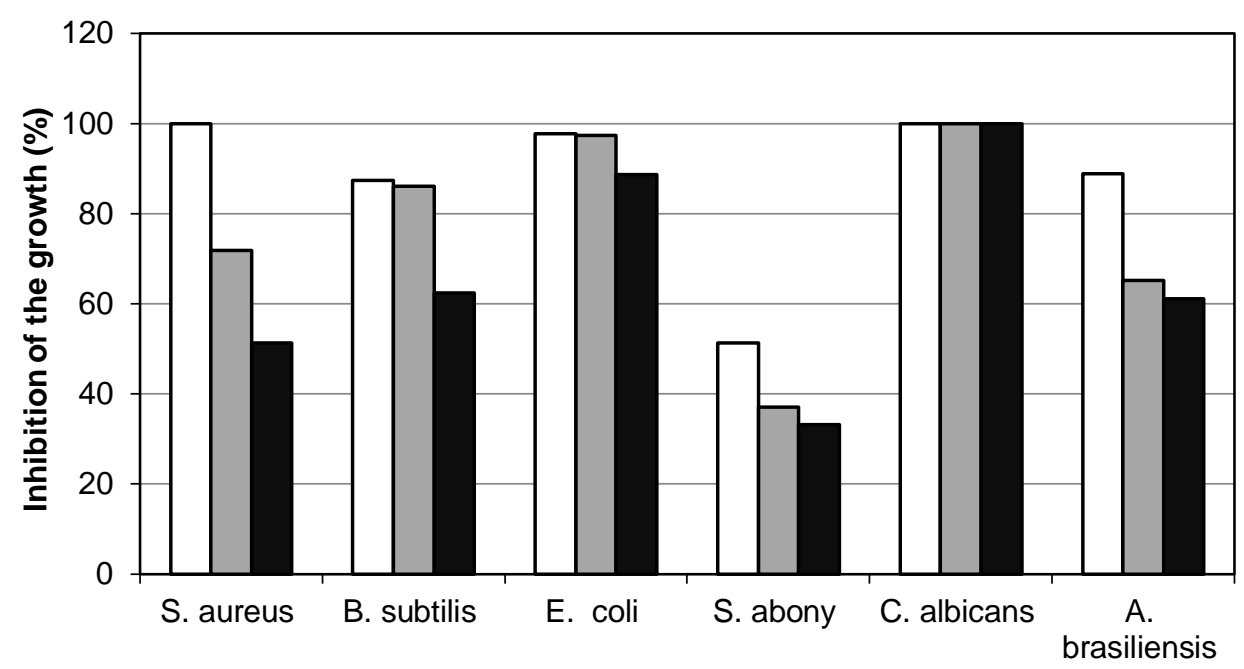

Test microorganisms

$\square 2$ hours $\quad$ व24 hours $\quad 5$ days

Figure 3. The antimicrobial effectiveness of unbleached cellulose wrapping paper coated with clary sage essential oil

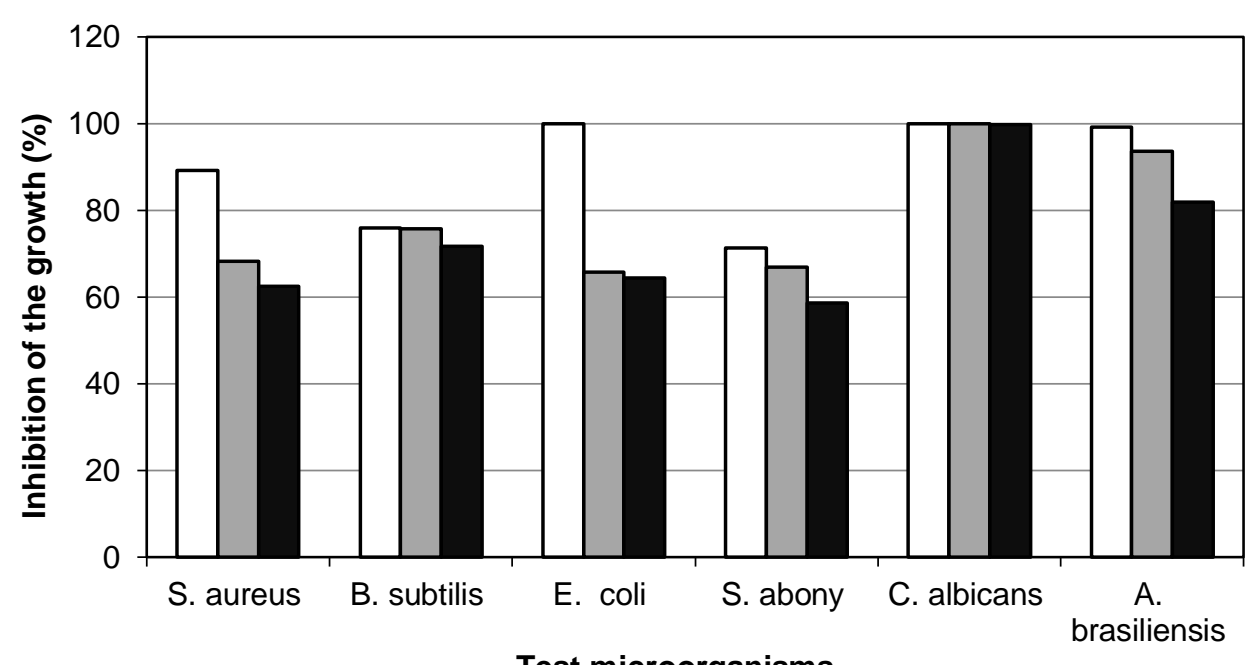

Test microorganisms

प2hours $\quad$ a24 hours $\mathbf{0} 5$ days

Figure 4. The antimicrobial effectiveness of recycled paper coated with clary sage essential oil 
The results obtained two hours after application of the clary sage essential oil to bleached cellulose wrapping paper (Figure 2) showed inhibitory action of $S$. aureus growth (100\% efficiency) and B. subtilis (97.8\%). Keeping the paper for $24 \mathrm{~h}$ did not affect its antimicrobial action against $S$. aureus, but it was decreased against B. subtilis (80.6\%). After 5 days of storage, antimicrobial effect decreased to $89.8 \%$ for $S$. aureus and $52.5 \%$ for $B$. subtilis.

Packaging paper had a full inhibitory effect on E. coli (100\%) two hours after clary sage essential oil application and weaker activity for $S$. abony, where viable cells decreased to $66.9 \%$. After $24 \mathrm{~h}$-storage, the antimicrobial action against E. coli and S. abony was found to be $56.3 \%$ and $60.5 \%$, respectively. The five-day storage period reduced the antimicrobial effectiveness to $48.9 \%$ for S. abony.

Full inhibition of $C$. albicans yeast growth and $83.9 \%$ in the A. brasiliensis mold growth was observed $2 \mathrm{~h}$ after the clary sage essential oil application. After $24 \mathrm{~h}$, the antimicrobial activity remained $100 \%$ in C. albicans and decreased to $66 \%$ in A. brasiliensis. After 5 days, this efficiency was $99.8 \%$ for C. albicans and $52.6 \%$ for A. brasiliensis.

Our results for the unbleached cellulose wrapping paper (Figure 3) showed an inhibition of the growth of Gram-positive test organisms S. aureus (100\%) and B. subtilis (87.3\%) two hours after the addition of clary sage essential oil. Keeping the paper for $24 \mathrm{~h}$ reduced the antibacterial action to 71.8 and $86.1 \%$, respectively. After a five-day storage period, it was determined that the antimicrobial effectiveness was $51.3 \%$ against $S$. aureus and $62.4 \%$ against $B$. subtilis.

Among the Gram-negative bacteria, S. abony was less affected than E. coli by unbleached cellulose paper. After $2 \mathrm{~h}$ of storage, the growth of $E$. coli was reduced to $97.8 \%$, while the growth of $S$. abony was found to be $51.3 \%$. After $24 \mathrm{~h}$ of paper storage, the effectiveness of the antimicrobial action against $E$. coli did not change significantly and was $97.3 \%$, while it was determined to be decreased to $37.1 \%$ for $S$. abony. Our results showed that the antimicrobial action was decreased to $88.7 \%$ for E. coli and $33.2 \%$ for S. abony after five-day storage.

Full inhibition of viable cells was detected in C. albicans $2 \mathrm{~h}$ after treatment of the wrapping paper with clary sage essential oil.

Unbleached cellulose wrapping paper started to inhibits the growth of A. brasiliensis (88.8\%) $2 \mathrm{~h}$ after the addition of the clary sage essential oil.

The usage of recycled paper (Figure 4 ), $2 \mathrm{~h}$ after the addition of clary sage essential oil, led to the suppression of the S. aureus (100\%) and B. subtilis (76\%) growth. After $24 \mathrm{~h}$ storage, its antibacterial action against $S$. aureus decreased to $89.2 \%$. After five days, the effectiveness of $S$. aureus was $68.2 \%$, while it was $71.7 \%$ against $B$. subtilis.

Recycled paper inhibited the growth of E. coli and S. abony bacteria by $100 \%$ and $71.3 \%$, respectively, two hours after the treatment with clary sage essential oil. After $24 \mathrm{~h}$ storage and 5 day-storage, its antimicrobial activity against $E$. coli decreased to $64.4 \%$.

Treatment of recycled paper led to $100 \%$ inhibition of C. albicans yeast growth and $99.2 \%$ of A. brasiliensis mold. After $24 \mathrm{~h}$, the effectiveness of the antimicrobial activity remained at the same level as both test microorganisms. After 5 days of storage, the antimicrobial effect was $99.7 \%$ for C. albicans and $81.9 \%$ for A. brasiliensis.

Previous studies showed that terpene essential oil components are effective on the biological activities on the common prominent pathogenic and spoilage food-related bacteria [14]. Our results for antimicrobial potential of clary sage essential oil are in agreement with the data found in the literature. Its high antimicrobial action could be probably due to the high content of oxygenated monoterpenes linalyl acetate and $\beta$-linalool. 


\section{Conclusion}

1. The results obtained showed high fungicidal efficacy for the three types of packaging materials. The suppressive action against $C$. albicans during the investigated shelf life varied about $100 \%$. A high antimicrobial efficiency against A. brasiliensis was found in the recycled paper $(99.2 \%-81.9 \%)$. The antimicrobial effectiveness in the bleached paper was found to be $83.9 \%$ and reduced to $52.6 \%$, while the antimicrobial activity of unbleached paper reduces from $88.8 \%$ at the beginning of the experiment to $61.2 \%$ at the end of the storage period.

2. The bactericidal efficacy of the three types of packaging papers, coated with clary sage essential oil against the Gram-positive test microorganisms tested was found to be among $100 \%$ and $76 \%$ and reduced to $89.8 \%-52.5 \%$ at the end of the five-day storage period. It was determined that the bactericidal effect of the tested packaging materials was lower than the Gram-negative bacterium S. abony.

3. Clary sage essential oil may be used in food packing as an antimicrobial agent in order to improve its quality and extend its shelf life.

Acknowledgments: The authors acknowledge the support of the Science Fund of the University of Ruse, Bulgaria (project 2019/BRz-01).

\section{References}

1. Georgiev E., Stoyanova A. (2006), Directory of specialization of aromatic and cosmetic industries, UFT Publ. House, Plovdiv.

2. Hristova Y., Gochev V., Wanner J., Jirovetz L., Schmidt E., Girova T., Kuzmanov A. (2013), Chemical composition and antifungal activity of essential oil of Salvia sclarea L. from Bulgaria against clinical isolates of Candida species, Journal of BioScience and Biotechnology, 2(1), pp. 39-44.

3. Cui H., Zhang X., Zhou H., Zhao C., Lin L. (2015), Antimicrobial activity and mechanisms of Salvia sclarea essential oil, Botanical Studies, 56 (16), pp. 1-8.

4. Wyrwa J., Barska A. (2017), Innovations in the food packaging market: active packaging, European Food Research Technology, 243, pp.1681-1692.

5. Yildirim S., Röcker B., Pettersen M. K., Nilsen-Nygaard J., Ayhan Z., Rutkaite R., Radusin T., Suminska P., Marcos B., Coma V. (2018), Active packaging Applications for Food, Comprehensive Reviews in Food Science and Food Safety, 17, pp. 165-199.

6. Rodríguez A., Batlle R., Nerín C. (2007), The use of natural essential oils as antimicrobial solutions in paper packaging. Part II, Progress in Organic Coatings 60, pp. 33-38.

7. Ivanova N., Bencheva S. Todorova D. (2009), A guide to exercises in the chemistry, technology and properties of paper, UCTM, Sofia.

8. Stoyanova A., Georgiev E., Atanasova T. (2007), A handbook for laboratory practice in essential oils, Acad. Publ. House of the University of Food Technologies, Plovdiv.

9. Adams R. P. (2001), Identification of essential oil components by gas chromatography/quadrupole mass spectroscopy. (R. P. Adams, Ed.), Carol Stream, USA: Allured Publishing Corporation 


\section{— Food Technology —}

10. Zaika L. L. (1988), Spices and herbs: Their antimicrobial activity and its determination Journal of Food Safety, 2, pp. 97-118, DOI: 10.1111/j.1745-4565.1988.tb00511.x

11. Cai J., Ping L., Xiaolan Z., Qingde S. (2006), Comparative analysis of clary sage (S. sclarea L.) oil volatiles by GC-FTIR and GC-MS, Food Chemistry, 99 (2), pp. 401407.

12. Carruba A., Torre R., Piccaglia R., Marotti M. (2002), Characterization of an Italian biotype of clary sage (Salvia sclarea L.) grown in a semi-arid Mediterranean environment, Flavour and Fragrance Journal, 17 (3) pp. 191-194.

13. Yousefzadi, M., Sonboli, A., Karimic, F., Ebrahimi, S. N., Asghari, B., A. Zeinalia (2007), Antimicrobial activity of some Salvia species essential oils from Iran, $Z$. Naturforsch. Pt C 62, (7-8), pp. 514-518.

14. Friedman M., Henika P.R., Mandrell R.E. (2002), Bactericidal activities of plant essential oils and some of their isolated constituents against Campylobacter jejuni, Escherichia coli, Listeria monocytogenes, and Salmonella enterica, Journal of Food Protectio, 65, pp. 1545-1560. 